\title{
ATP-sensitive potassium channelopathies: focus on insulin secretion
}

Frances M. Ashcroft

University Laboratory of Physiology, Oxford University, Oxford, United Kingdom.

\begin{abstract}
ATP-sensitive potassium $\left(\mathrm{K}_{\mathrm{ATP}}\right)$ channels, so named because they are inhibited by intracellular ATP, play key physiological roles in many tissues. In pancreatic $\beta$ cells, these channels regulate glucose-dependent insulin secretion and serve as the target for sulfonylurea drugs used to treat type 2 diabetes. This review focuses on insulin secretory disorders, such as congenital hyperinsulinemia and neonatal diabetes, that result from mutations in $K_{\mathrm{ATP}}$ channel genes. It also considers the extent to which defective regulation of $K_{\mathrm{ATP}}$ channel activity contributes to the etiology of type 2 diabetes.
\end{abstract}

\section{General properties of ATP-sensitive potassium channels}

\section{Physiological roles}

ATP-sensitive potassium $\left(\mathrm{K}_{\mathrm{ATP}}\right)$ channels couple cell metabolism to electrical activity of the plasma membrane by regulating membrane $\mathrm{K}^{+}$fluxes (1). A reduction in metabolism opens $\mathrm{K}_{\mathrm{ATP}}$ channels, producing $\mathrm{K}^{+}$efflux, membrane hyperpolarization, and suppression of electrical activity. Conversely, increased metabolism closes $\mathrm{K}_{\mathrm{ATP}}$ channels. The consequent membrane depolarization stimulates electrical activity and may thereby trigger cellular responses such as the release of hormones and neurotransmitters, or muscle contraction.

Studies on isolated cells and tissues, and more recently on genetically modified mice and patients with mutations in $\mathrm{K}_{\mathrm{ATP}}$ channel genes, have demonstrated that $\mathrm{K}_{\mathrm{ATP}}$ channels play a multitude of physiological roles (1). They contribute to glucose homeostasis by regulating insulin secretion from pancreatic $\beta$ cells (2-7), glucagon secretion from pancreatic $\alpha$ cells (8), somatostatin secretion from D cells (9), and GLP-1 secretion from L cells (10). In ventromedial hypothalamic neurons they mediate the counter-regulatory response to glucose (11), and in arcuate nucleus neurons they may be involved in appetite regulation (12). In these glucose-sensing cells, $\mathrm{K}_{\mathrm{ATP}}$ channels respond to fluctuating changes in blood glucose concentration. In many other tissues, however, they are largely closed under resting conditions and open only in response to ischemia, hormones, or neurotransmitters. In cardiac muscle and central neurons the resulting reduction in electrical activity helps protect against cardiac stress and brain seizures (13-17). $\mathrm{K}_{\text {ATP }}$ channels are involved in ischemic preconditioning in heart (18) and the regulation of vascular smooth muscle tone (opening of $\mathrm{K}_{\mathrm{ATP}}$ channels leads to relaxation) (19-21). They also modulate electrical activity and neurotransmitter release at synapses

\footnotetext{
Nonstandard abbreviations used: DEND syndrome, developmental delay, muscle weakness, eppilepsy, dysmorphic features, and neonatal diabetes; GCK, glucokinase; $\mathrm{GDH}$, glutamate dehydrogenase; $\mathrm{HI}$, congenital hyperinsulinism of infancy; $\mathrm{K}_{\mathrm{ATP}}$, ATP-sensitive potassium (channel); MIDD, maternally inherited diabetes with deafness; MODY, maturity-onset diabetes of the young; PNDM, permanent neonatal diabetes mellitus; Po, open probability; SCHAD, L-3-hydroxyacyl-CoA dehydrogenase; SUR, sulfonylurea receptor; TNDM, transient neonatal diabetes mellitus.

Conflict of interest: The author has declared that no conflict of interest exists.

Citation for this article: J. Clin. Invest. 115:2047-2058 (2005).

doi:10.1172/JCI25495.
}

in many brain regions, including the hippocampus, substantia nigra, and hypothalamus (12, 22-27).

Given their critical role in regulating electrical excitability in many cells, it is perhaps not surprising that disruption of $K_{A T P}$ channel function can lead to disease. To date, mutations in $\mathrm{K}_{\mathrm{ATP}}$ channel genes have been shown to cause neonatal diabetes $(7,28-33)$, hyperinsulinemia $(6,34-40)$, and dilated cardiomyopathy (41) in humans. Studies on genetically modified mice have also implicated impaired $\mathrm{K}_{\mathrm{ATP}}$ channel function in Prinzmetal angina (20-21). This review will focus on recent advances in our understanding of the role of the $\mathrm{K}_{\text {ATP }}$ channel in insulin secretory disorders.

The central importance of $\mathrm{K}_{\mathrm{ATP}}$ channels in insulin secretion was first established over 20 years ago (Figure 1) (2, 42). At substimulatory glucose concentrations, $\mathrm{K}^{+}$efflux through open $\mathrm{K}_{\mathrm{ATP}}$ channels keeps the $\beta$ cell membrane at a negative potential at which voltage-gated $\mathrm{Ca}^{2+}$ channels are closed. An increase in plasma glucose stimulates glucose uptake and metabolism by the $\beta$ cell, producing changes in cytosolic nucleotide concentrations that result in closure of $\mathrm{K}_{\mathrm{ATP}}$ channels. This leads to a membrane depolarization that opens voltage-gated $\mathrm{Ca}^{2+}$ channels, initiating $\beta$ cell electrical activity, $\mathrm{Ca}^{2+}$ influx, a rise in intracellular calcium concentration $\left(\left[\mathrm{Ca}^{2+}\right]_{i}\right)$, and thereby exocytosis of insulin granules. Glucose metabolism has additional effects on insulin release $(5,43)$, but under physiological conditions $\mathrm{K}_{\mathrm{ATP}}$ channel closure is an essential step in stimulus-secretion coupling in $\beta$ cells. This explains why sulfonylurea drugs, such as tolbutamide and glibenclamide, which close $\mathrm{K}_{\text {ATP }}$ channels (44), are such effective insulin secretagogues and are widely used to treat type 2 diabetes. They bypass $\beta$ cell metabolism by binding directly to the $\mathrm{K}_{\mathrm{ATP}}$ channel. Conversely, the $\mathrm{K}$ channel opener diazoxide opens $\mathrm{K}_{\mathrm{ATP}}$ channels and inhibits insulin secretion, independently of blood glucose levels (45).

\section{Metabolic regulation}

$\mathrm{K}_{\mathrm{ATP}}$ channels are subject to complex regulation by numerous cytosolic factors, the most important being the adenine nucleotides ATP and ADP, which interact with 2 sites on the channel, one inhibitory and the other stimulatory (46-49). These can be distinguished experimentally because nucleotide binding to the stimulatory, but not the inhibitory, site requires $\mathrm{Mg}^{2+}(47,49)$. Thus, in the absence of $\mathrm{Mg}^{2+}$ only the inhibitory effect is observed. Within the cell, however, where $\mathrm{Mg}^{2+}$ is always present, channel activity is determined by the balance between the inhibitory and stimulatory effects of 
A

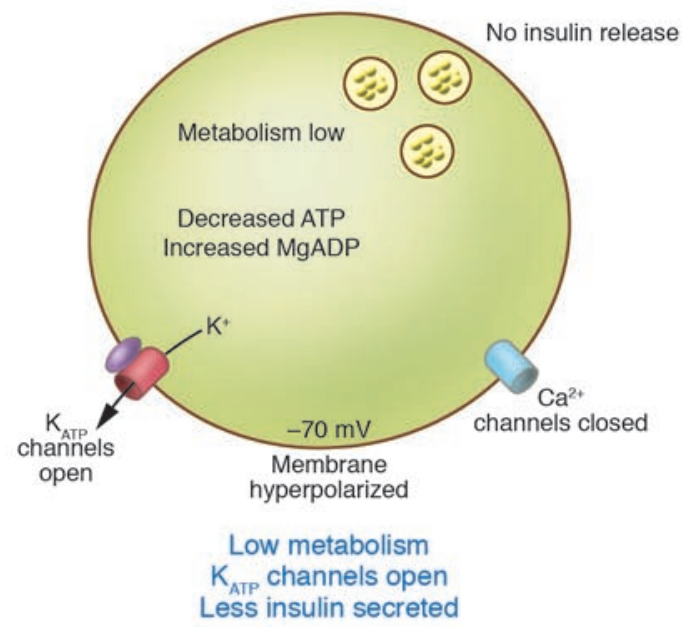

\section{Gain-of-function-mutations in Kir6.2}

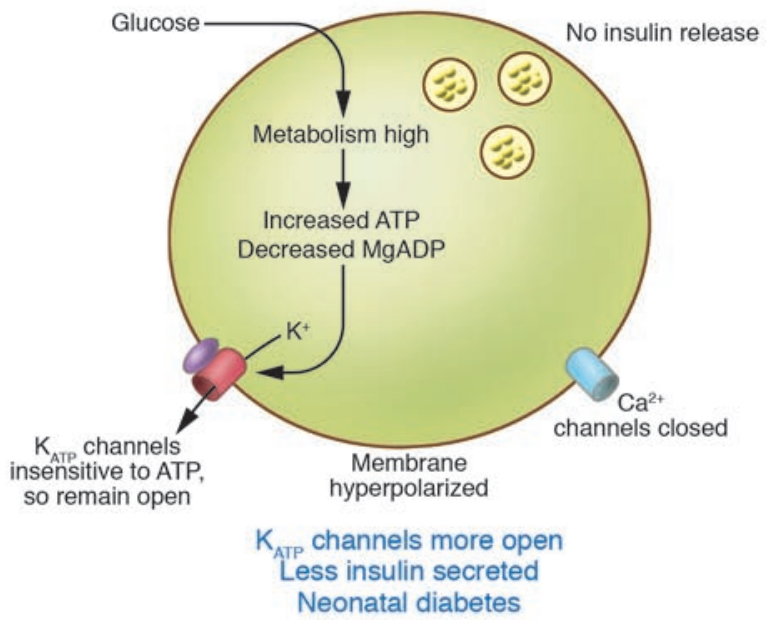

B Plasma glucose high

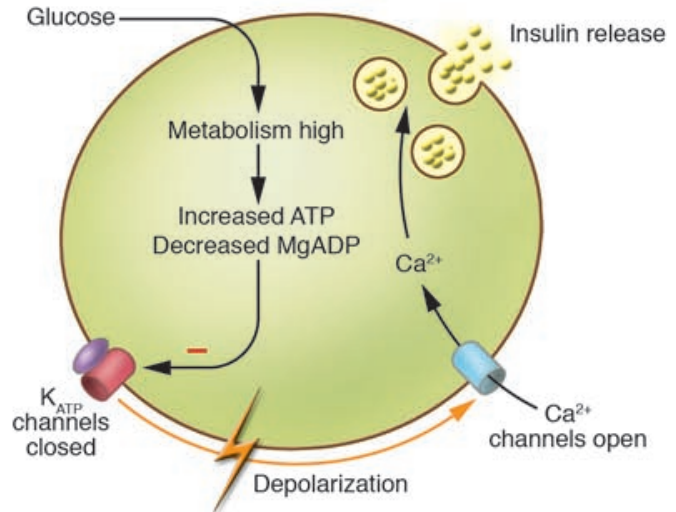

High metabolism

$\mathrm{K}_{\text {ATP }}$ channels closed

Insulin secreted

\section{Loss-of-function-mutations in SUR1 and Kir6.2}

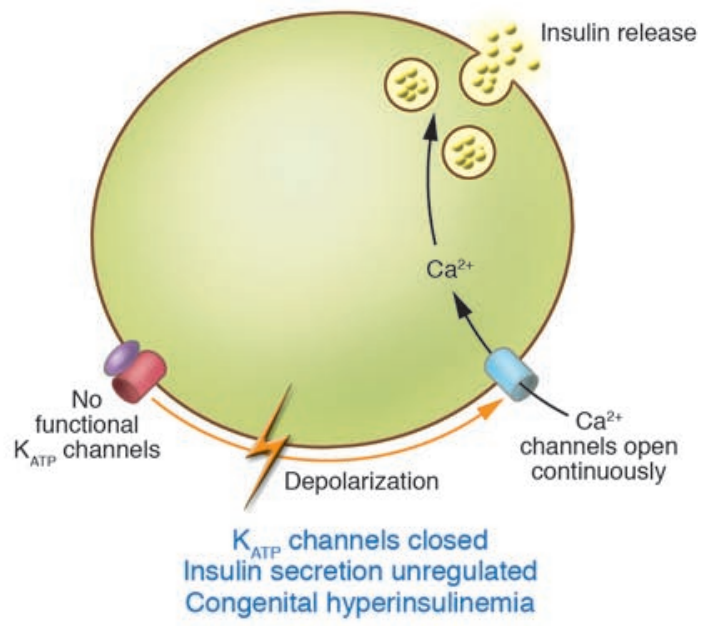

Figure 1

The $\mathrm{K}_{\text {ATP }}$ channel couples glucose metabolism to insulin secretion. Glucose enters the cell via the GLUT2 transporter, and via glycolytic and mitochondrial metabolism leads to an increase in ATP and a fall in MgADP in the immediate vicinity of the $\mathrm{K}_{\text {ATP }}$ channel. This results in $\mathrm{K}_{\text {ATP }}$ channel closure, membrane depolarization, opening of voltage-gated $\mathrm{Ca}^{2+}$ channels, $\mathrm{Ca}^{2+}$ influx, and exocytosis of insulin granules.

nucleotides. At nucleotide concentrations found in cells, ATP is predicted to block the channel and MgADP to reverse channel inhibition by ATP $(42,49)$. Consequently, reciprocal changes in the intracellular concentrations of ATP and MgADP are suggested to mediate metabolic regulation of the $\mathrm{K}_{\mathrm{ATP}}$ channel.

\section{Molecular structure}

The $\mathrm{K}_{\text {ATP }}$ channel is an octameric complex of 4 Kir6.x and 4 SURx subunits (Figure 2) (50,51). The pore-forming Kir6.x subunit belongs to the inwardly rectifying family of potassium channels (52-54). There are 2 isoforms: Kir6.1, which is found in vascular smooth muscle (54), and Kir6.2, which has a widespread tissue distribution (53). Binding of ATP to Kir6.x causes $\mathrm{K}_{\text {ATP }}$ channel closure $(48,55)$.

The sulfonylurea receptor (SUR) belongs to the ABC transporter family (56). It functions as a regulatory subunit, endowing the channel with sensitivity to (a) stimulation by $\mathrm{Mg}$ nucleotides, via its 2 cytosolic nucleotide-binding domains $(57,58)$; (b) activation by K channel opener drugs (e.g., diazoxide); and (c) inhibition by sulfonylureas (e.g., glibenclamide, tolbutamide) $(48,56)$. Variations in SUR subunit composition produce $\mathrm{K}_{\mathrm{ATP}}$ channels with different sensitivities to metabolism and drug regulation $(22,44)$. SUR1 is found in pancreas and brain (56), SUR2A in cardiac and skeletal muscle $(59,60)$, and SUR2B in a variety of tissues including brain and smooth muscle (61).

\section{A digression on $\beta$ cell electrical activity}

Electrical activity of the $\beta$ cell membrane, in the form of $\mathrm{Ca}^{2+}-$ dependent action potentials, is essential for insulin secretion: no insulin is secreted in its absence, and the extent of insulin secretion and that of electrical activity are directly correlated (62). The 
$\mathrm{K}_{\text {ATP }}$ channel thus both initiates electrical activity and regulates its extent at suprathreshold glucose concentrations $(2,63)$. This is because the resting potential in pancreatic $\beta$ cells is primarily controlled by the $\mathrm{K}_{\mathrm{ATP}}$ channel.

The $\mathrm{K}_{\text {ATP }}$ channel also determines the electrical resistance of the $\beta$ cell membrane, which is low when $K_{\text {ATP }}$ channels are open and high when they are closed. The membrane potential is given by the product of the electrical resistance of the membrane and the current flowing across it. This means that when $\mathrm{K}_{\mathrm{ATP}}$ channels are open and membrane resistance is low, small currents will affect the membrane potential (and thus insulin secretion) only minimally, whereas when $\mathrm{K}_{\mathrm{ATP}}$ channels are (largely) closed and membrane resistance is high, the same current will elicit $\beta$ cell depolarization, electrical activity, and insulin secretion. This explains why potentiators of insulin secretion such as acetylcholine and arginine, which produce small inward currents $(64,65)$, are effective secretagogues

A

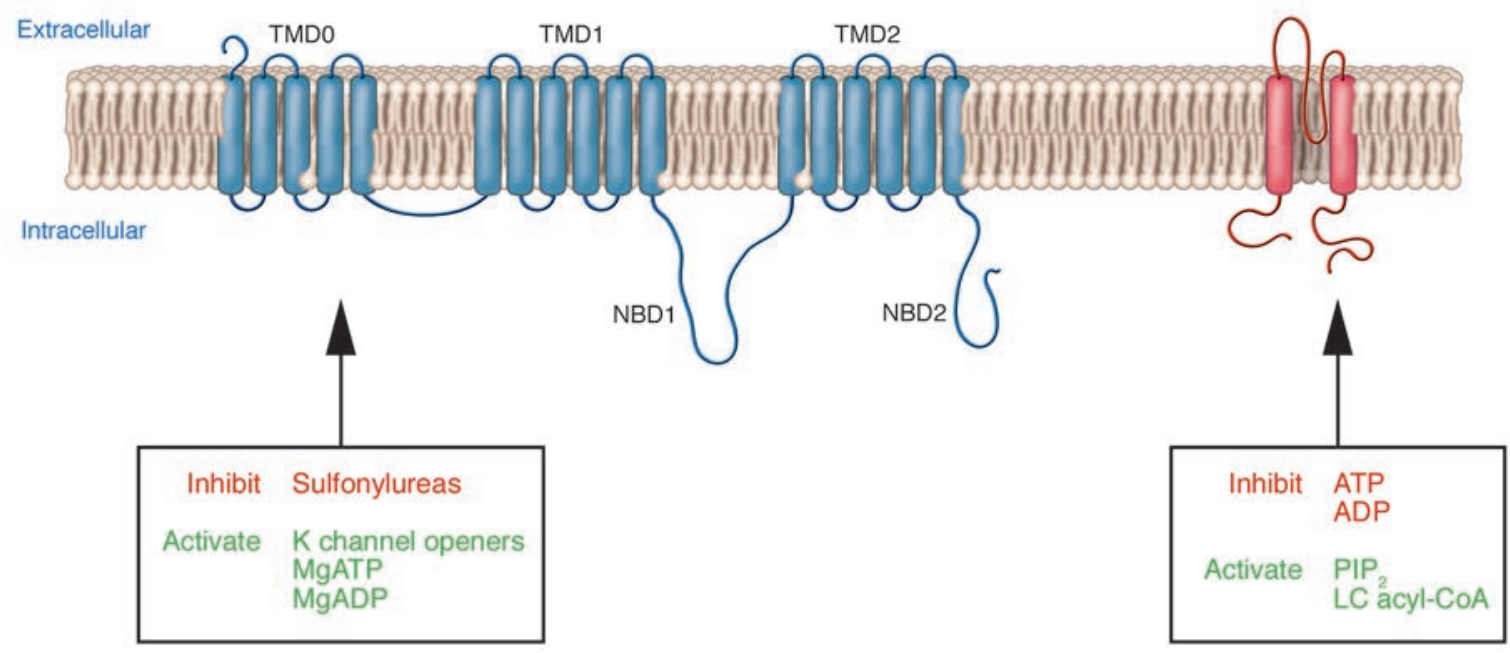

B

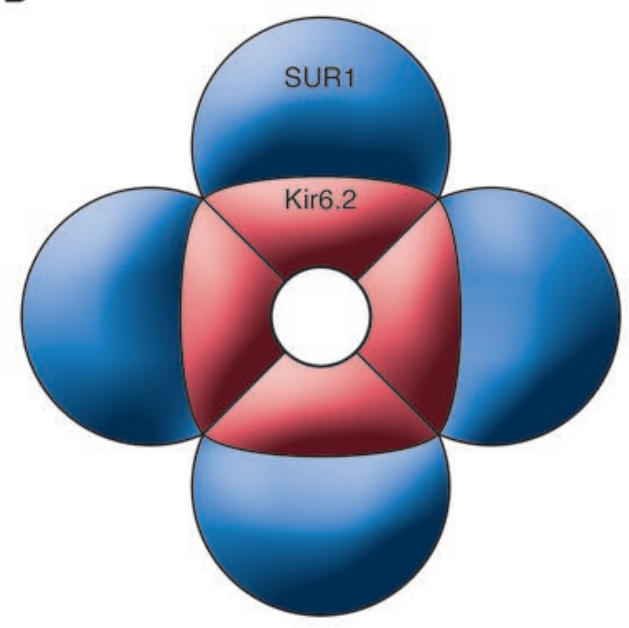

C

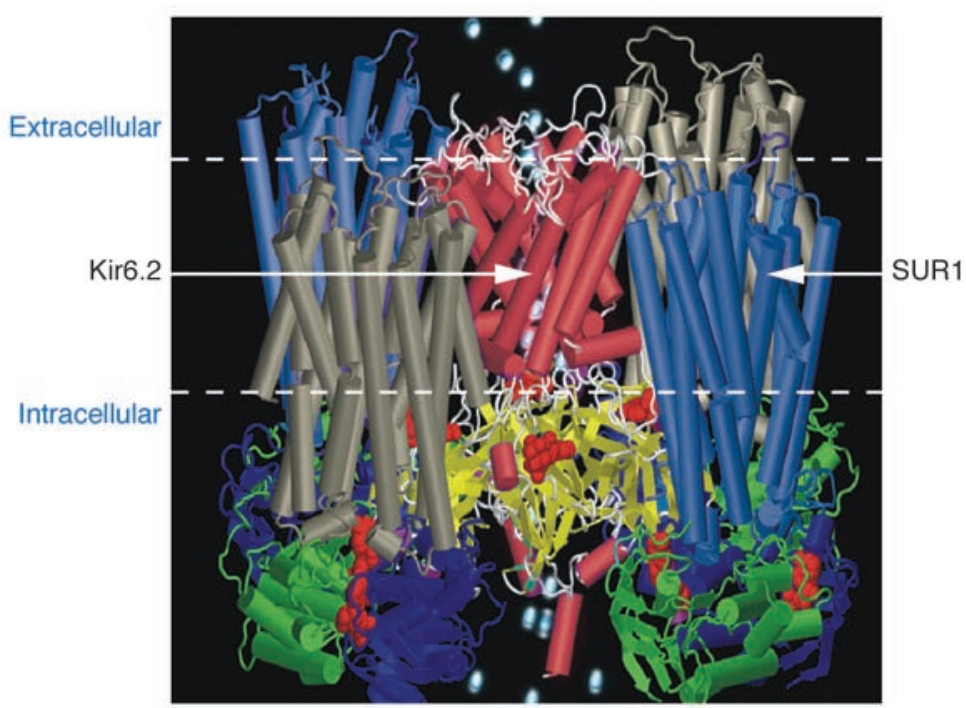

\section{Figure 2}

Molecular structure of the $\mathrm{K}_{\text {ATP }}$ channel. (A) Schematic representation of the transmembrane topology of a single SURx (left) or Kir6.x (right) subunit. Mg-nucleotide binding/hydrolysis at the nucleotide-binding domains (NBD1, NBD2) of SUR stimulates channel activity. Sulfonylureas (stimulatory) and K channel openers (inhibitory) also bind to SUR1. Binding of ATP or ADP to Kir6.2 closes the pore, an effect that does not require $\mathrm{Mg}^{2+}$. Conversely, binding of phospholipids such as $\mathrm{PIP}_{2}$, or long-chain (LC) acyl-coAs, stimulates $\mathrm{K}_{\text {ATP }}$ channel activity and decreases its ATP sensitivity. (B) Schematic representation of the octameric $\mathrm{K}_{\text {ATP }}$ channel complex viewed in cross section. Four Kir6.2 subunits come together to form the pore through which $\mathrm{K}^{+}$ions move, and each is associated with a regulatory SURx subunit. (C) Model of how SUR1 and Kir6. 2 might assemble to form the $\mathrm{K}_{\text {ATP }}$ channel. The SUR model is described in ref. 115 and the Kir6.2 model in ref. 116 . The model illustrates that the channel complex contains 4 ATP-binding sites (on Kir6.2) and 8 Mg nucleotide-binding sites (on SUR1). 
Table 1

Kir6.2 mutations associated with insulin secretory disorders

\begin{tabular}{|c|c|c|c|c|c|c|c|}
\hline \multirow[t]{2}{*}{ Position } & \multirow[t]{2}{*}{ Mutation } & \multicolumn{3}{|c|}{ Clinical phenotype } & \multicolumn{2}{|c|}{ Functional effect } & \multirow[t]{2}{*}{ Reference } \\
\hline & & Insulin secretion & $\begin{array}{l}\text { Neurol. } \\
\text { features }\end{array}$ & Epilepsy & ATP sensitivity & Po & \\
\hline $\mathrm{N}$ terminus & Y12STOP & $\mathrm{HI}$ & & & & & 36 \\
\hline $\mathrm{N}$ terminus & F35L & PNDM (1) & No & No & & & 29 \\
\hline $\mathrm{N}$ terminus & F35V & PNDM (1) & No & No & & & 28 \\
\hline $\mathrm{N}$ terminus & C42R & PNDM (1), TNDM (1), MODY (2) & No & No & Reduced & & 86 \\
\hline $\mathrm{N}$ terminus & R50P & PNDM (1) & & & Reduced & & 30,89 \\
\hline $\mathrm{N}$ terminus & Q52R & DEND syndrome (1) & Yes & Yes & Reduced & Increased & 7,83 \\
\hline $\mathrm{N}$ terminus & G53N & PNDM (1) & No & No & & & 29 \\
\hline $\mathrm{N}$ terminus & G53R & TNDM (2) & No & No & Reduced & & 33 \\
\hline $\mathrm{N}$ terminus & G53S & TNDM (3) & No & No & Reduced & & 33 \\
\hline Slide helix & V59G & DEND syndrome (1) & Yes & Yes & Reduced & Increased & 7 \\
\hline Slide helix & V59M & Intermediate DEND (10) & Yes $(7 / 10)$ & No & Reduced & Increased & $7,28,30,83$ \\
\hline TMs & K67N & $\mathrm{HI}$ & & & & & 117,118 \\
\hline TMs & A101D & $\mathrm{HI}$ & & & & & 38 \\
\hline TMs & $\mathrm{R} 136 \mathrm{~L}$ & $\mathrm{HI}$ & & & & & 38 \\
\hline TMs & L147P & $\mathrm{HI}$ & & & & & 37 \\
\hline TMs & $\mathrm{C} 166 \mathrm{~F}$ & DEND syndrome (1) & Yes & Yes & & & 85 \\
\hline TMs & K170R & PNDM (1) & No & No & & & 30 \\
\hline TMs & K170N & PNDM (1) & Yes & No & & & 30 \\
\hline C terminus & I182V & TNDM (1) & No & No & Reduced & Increased & 33 \\
\hline C terminus & $\mathrm{R} 201 \mathrm{C}$ & PNDM (6) & Yes $(2 / 6)$ & No & Reduced & Unaffected & $7,29,30-32$ \\
\hline C terminus & $\mathrm{R} 201 \mathrm{H}$ & PNDM (12) & No & No & Reduced & Unaffected & $7,28,29,31,83$ \\
\hline C terminus & P254L & $\mathrm{HI}$ & & & & & 118 \\
\hline C terminus & I296L & DEND syndrome (1) & Yes & Yes & Reduced & $\mathrm{H}$ increased & 7,84 \\
\hline C terminus & $\mathrm{R} 301 \mathrm{H}$ & $\mathrm{HI}$ & & & & & 38 \\
\hline $\mathrm{C}$ terminus & E322K & PNDM (1) & No & No & & & 29 \\
\hline C terminus & Y330C & PNDM (3) & Yes $(2 / 3)$ & No & & & 28,29 \\
\hline C terminus & F333I & PNDM (1) & No & No & & & 28 \\
\hline
\end{tabular}

Mutations in Kir6.2 that cause HI or monogenic diabetes. TMs, transmembrane domains; neurol. features, neurological features (i.e., developmental delay, epilepsy, or other symptoms). The numbers in parentheses refer to the number of cases. Position refers to the position of the residue in the primary sequence of the protein.

only at glucose concentrations that shut most $\mathrm{K}_{\mathrm{ATP}}$ channels. It also implies that these agents will be more effective in disease states that lead to decreased $\mathrm{K}_{\mathrm{ATP}}$ channel activity (congenital hyperinsulinism of infancy) and less effective under conditions that enhance $\mathrm{K}_{\mathrm{ATP}}$ channel activity (diabetes).

The $\mathrm{K}_{\text {ATP }}$ channel plays a lesser role in regulating electrical activity of muscle and nerve cells because additional channels contribute to the resting membrane potential and membrane resistance. Thus, equivalent changes in $\mathrm{K}_{\mathrm{ATP}}$ channel activity are expected to have less dramatic effects in these cell types.

\section{Congenital hyperinsulinism of infancy}

Congenital hyperinsulinism of infancy (HI) is characterized by continuous, unregulated insulin secretion despite severe hypoglycemia (6), and, without therapy, the hypoglycemia may cause irreversible brain damage. The disease usually presents at birth or within the first year of life. In the general population, the incidence is estimated as 1 in 50,000 live births, but this can be higher in isolated communities (e.g., 1 in 2,500 in the Arabian peninsula) (6, 34). Most cases of HI are sporadic, but familial forms have been also described, and the disease may result from homozygous, compound heterozygous, or heterozygous mutations $(35,36,39,40)$. Mild cases can be managed with diazoxide or even diet, but more severe forms require subtotal pancreatectomy (commonly about
90-95\%). This results in pancreatic insufficiency, and a high incidence of iatrogenic diabetes. The main features of HI are summarized here; further details can be found in other reviews $(6,34,66)$.

\section{Functional effects of HI mutations}

Mutations in 5 different genes can produce HI: the $\mathrm{K}_{\mathrm{ATP}}$ channel subunits $\operatorname{SUR} 1(6,35)$ and $\operatorname{Kir} 6.2(\operatorname{KCNJ11})(36,37)$, and the metabolic enzymes glucokinase $(G C K)(66,67)$, glutamate dehydrogenase (GLUD1) (68), and short-chain L-3-hydroxyacyl-CoA dehydrogenase (SCHAD) (69). However, in about half of patients the genetic basis of HI has not yet been determined.

Mutations in SUR1 $(A B C C 8)$ are the most common cause of $\mathrm{HI}$, accounting for almost $50 \%$ of cases $(6,34)$. More than 100 mutations have been described, distributed throughout the gene. They comprise 2 functional classes: those in which the protein is not present in the surface membrane (class I), and those in which the channel is present in the plasma membrane but is always closed, independent of the metabolic state of the cell (class II). Class I mutations are characterized by loss of $\mathrm{K}_{\mathrm{ATP}}$ channels in the plasma membrane, which may result from impaired SUR1 synthesis, abnormal SUR1 maturation, defective channel assembly, or faulty surface membrane trafficking (6, 70-72) (since SUR1 is required for surface expression of Kir6.2 [ref. 73], Kir6.2 is also absent). Class II mutations impair the 
ability of MgADP to stimulate channel activity $(6,39,57)$, so that ATP inhibition becomes dominant and the $\mathrm{K}_{\mathrm{ATP}}$ channel is permanently closed even at low glucose concentrations. Many, but not all, class II mutations reside in the nucleotide-binding domains of SUR1. In general, class I mutations produce more severe disease, whereas some class II mutations cause a milder phenotype because a residual response to MgADP remains (39, $40)$. However, there is no precise genotype-phenotype correlation, and the same mutation can produce HI with differing degrees of severity in different people.

Mutations in Kir6.2 (KCNJ11) that cause HI are much rarer than those in SUR1 (Table 1) (36-38). They also act by reducing, or abolishing, $\mathrm{K}_{\mathrm{ATP}}$ channel activity in the surface membrane. Because the $\mathrm{K}_{\mathrm{ATP}}$ channel sets the $\beta$ cell membrane potential, decreased channel activity produces a persistent membrane depolarization and continuous insulin secretion, irrespective of the blood glucose level (Figure 1).

The glycolytic enzyme glucokinase (GCK) and the mitochondrial enzyme glutamate dehydrogenase (GDH) play key roles in $\beta$ cell metabolism. It is therefore reasonable to postulate that the gain-of-function mutations in these genes produce HI by increasing ATP synthesis and shifting the $\mathrm{K}_{\mathrm{ATP}}$ channel inhibition curve to lower glucose concentrations. As a result, $\mathrm{K}_{\mathrm{ATP}}$ channel activity would decrease, stimulating insulin secretion. Mutations in GDH cause an additional hyperammonemia and an enhanced insulin response to a protein meal or the amino acid leucine (68). The latter may be explained by allosteric stimulation of GDH by leucine, leading to enhanced ATP generation. With one exception (74), the mutations in GCK and GLUD1 (encoding GDH) reported to date produce a mild form of $\mathrm{HI}$ that does not require pancreatectomy. It is still unclear how mutations in SCHAD, which is involved in mitochondrial fatty acid oxidation, cause HI.

Certain mutations in SUR1, for example R1353H, produce familial leucine-sensitive HI, in which hypoglycemia is provoked by leucine (40). The phenotype is less severe, consistent with the fact that mutant $\mathrm{K}_{\mathrm{ATP}}$ channels show a partial response to MgADP. As leucine stimulates $\beta$ cell ATP production, it seems possible that some SUR1 (and GDH) mutations cause a partial $\beta$ cell depolarization, which is insufficient to elicit electrical activity and insulin release in the resting state. However, further $\mathrm{K}_{\mathrm{ATP}}$ channel closure as a result of leucine-stimulated ATP production enhances membrane depolarization, thus eliciting insulin secretion. This hypothesis is supported by the fact that leucine can trigger insulin secretion in normal subjects, although not enough to provoke hypoglycemia, and that enhanced leucine sensitivity is produced by prior treatment with tolbutamide, which closes $\mathrm{K}_{\mathrm{ATP}}$ channels (75).

Although $\mathrm{HI}$ is often associated with neurological problems, it is difficult to assess whether these result from hypoglycemia prior to diagnosis and treatment, or are a direct consequence of the mutation itself. In many extrapancreatic tissues, $\mathrm{K}_{\mathrm{ATP}}$ channels are closed at rest, so loss-of-function mutations might be expected to have little effect. Furthermore, sulfonylurea therapy in type 2 diabetic patients has few side effects (though it is not clear whether these drugs access brain $\mathrm{K}_{\mathrm{ATP}}$ channels).

\section{Implications for therapy}

In general, mutations in SUR1 and Kir6.2 cause a severe form of $\mathrm{HI}$ that is refractory to diazoxide $(6,38)$ and requires subtotal pancreatectomy. This arises because $\mathrm{K}_{\mathrm{ATP}}$ channels are either absent or drug-resistant. In contrast, HI caused by mutations in GCK, GLUD1, or SCHAD responds well to diazoxide (6), as $\mathrm{K}_{\mathrm{ATP}}$ channel properties are normal. In these patients, opening of $K_{\text {ATP }}$ channels by diazoxide hyperpolarizes the $\beta$ cell and so reduces electrical activity and insulin secretion despite high plasma glucose levels. Patients with GCK mutations may even be able to control their symptoms by eating regularly (76). This is because GCK mutations merely reset the threshold for glucose-stimulated insulin secretion, so that insulin release is still regulated, although the amount is abnormally high for the blood glucose level. Thus, genotyping HI patients may help determine correct therapy.
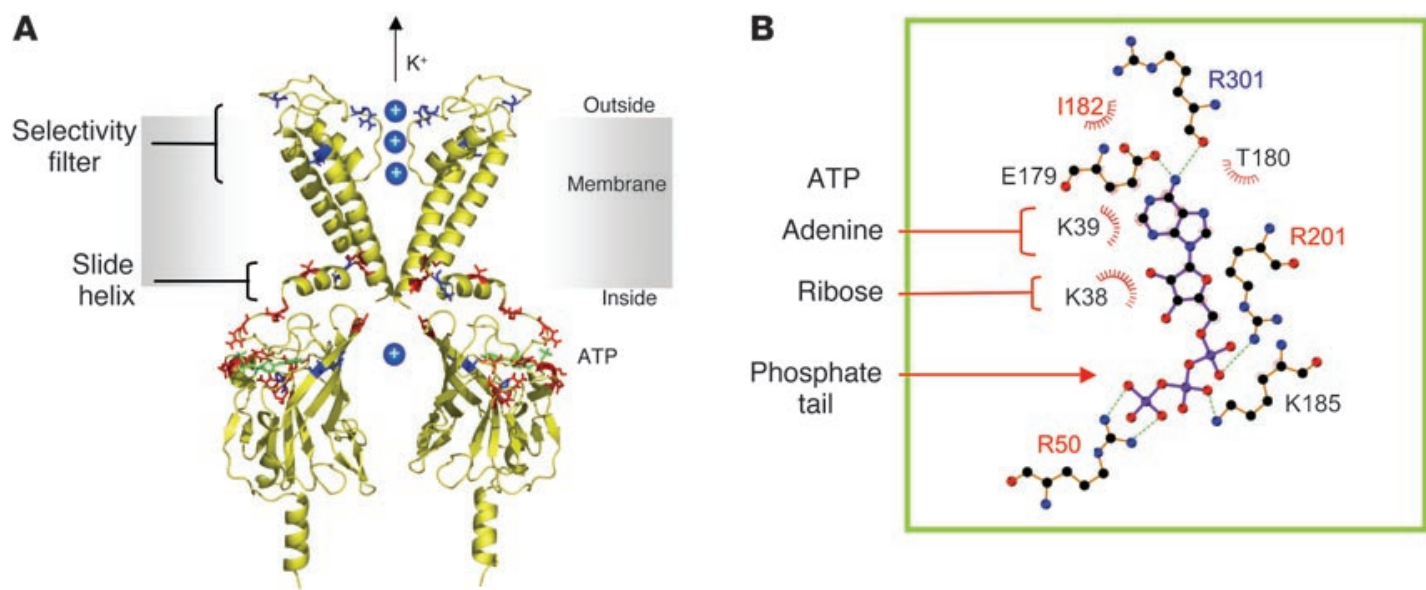

\section{Figure 3}

Location of disease-causing mutations in Kir6.2. (A) Structural model of Kir6.2 (116) viewed from the side. For clarity, only 2 transmembrane domains, and 2 separate cytosolic domains, are shown. Residues mutated in neonatal diabetes are shown in red, and those that cause hyperinsulinism of infancy in blue. ATP (green) is docked into its binding site. Of the residues implicated in neonatal diabetes, R50, R201, Y330C, and F333I lie close to the ATP-binding site; F35, C42, and E332K at the interface between Kir6.2 subunits; Q52 and G53 in a region postulated to interface with SUR1; and V59, C166, and I296L within regions of the channel involved in gating. (B) Close-up of the putative ATP-binding site with residues lying within $3.5 \AA$ of ATP indicated. Residues mutated in neonatal diabetes are shown in red. Part B is adapted with permission from The EMBO Journal (116). 


\section{Table 2}

Disease severity correlates with extent of MgATP block

$\begin{array}{lccc}\text { Mutation } & \text { Phenotype } & \begin{array}{c}\text { Fraction unblocked I- } \mathbf{K}_{\text {ATP }} \\ \text { at 1 mM MgATP }\end{array} & \text { Reference } \\ \text { WT } & \text { None } & 2.4 \% & 33 \\ \text { G53S } & \text { TNDM } & 6 \% & 33 \\ \text { G53R } & \text { TNDM } & 11 \% & 33 \\ \text { I182V } & \text { TNDM } & 12 \% & 33 \\ \text { R201H } & \text { PNDM } & 22 \% & 33 \\ \text { I296L } & \text { DEND syndrome } & 36 \% & 84\end{array}$

Fraction of unblocked $\mathrm{K}_{\mathrm{ATP}}$ current measured in the heterozygous state in the presence of $1 \mathrm{mM}$ ATP for WT (Kir6.2/SUR1) and Kir6.2 mutant channels.

Both sulfonylureas and $\mathrm{K}$ channel openers can act as chemical chaperones and correct surface trafficking defects associated with some SUR1 mutations $(71,72)$. As the resulting $\mathrm{K}_{\mathrm{ATP}}$ channels have normal nucleotide sensitivity, drugs with similar chaperone activity that do not block the channel could potentially be useful for treating HI. However, not all mutations can be rescued in this way, and the pharmacology varies with the mutation. Thus, the K channel opener diazoxide corrected trafficking of SUR-R1349H (an effect reversed by glibenclamide) (71), whereas the sulfonylureas glibenclamide and tolbutamide, but not diazoxide, restored surface expression of SUR1-A116P and SUR1-V187D (72). It may not be simple, therefore, to develop drugs that correct surface trafficking generically.

\section{HI and diabetes}

There is accumulating evidence that HI caused by some SUR1 mutations can progress to type 2 diabetes in later life $(39,40)$. This is hypothesized to occur because continuous $\beta$ cell membrane depolarization, due to reduced $\mathrm{K}_{\mathrm{ATP}}$ channel activity, causes a maintained influx of $\mathrm{Ca}^{2+}$ that activates apoptosis, thereby reducing $\beta$ cell mass and insulin secretion. Studies on Kir6.2 knockout mice support this idea $(4,77)$. Except where no surgery has been carried out (39), it is difficult to distinguish whether SUR1 mutations predispose human patients to type 2 diabetes, or whether the diabetes results from early pancreatectomy. It is also uncertain whether HI mutations in other genes enhance susceptibility to diabetes.

\section{Permanent neonatal diabetes}

Neonatal diabetes mellitus is characterized by hyperglycemia requiring insulin therapy that develops within the first 6 months of life. It is a rare disorder affecting 1 in 400,000 live births (78), and it may be either transient (TNDM) or permanent (PNDM). Approximately $50 \%$ of PNDM cases result from heterozygous gain-of-function mutations in Kir6.2 (7, 28-33). Homozygous loss-of-function mutations in GCK are a rare cause of the disease $(66,79,80)$ and are thought to act by impairing $\mathrm{K}_{\mathrm{ATP}}$ channel closure indirectly, via reduced metabolic generation of ATP. Transient neonatal diabetes (TNDM), which resolves with a median of 3 months, is usually associated with an abnormality of imprinting in chromosome 6q24 (81). However, heterozygous mutations in Kir6.2 can produce a remitting relapsing form of neonatal diabetes that resembles TNDM (33).

To date, 20 mutations in 14 different residues have been reported to cause neonatal diabetes (Table 1 ). Their location in a struc- tural model of Kir6.2 is shown in Figure 3. They form striking clusters in the putative ATP-binding site, at the inner end of the transmembrane domains (where the second transmembrane helices come together to form the inner mouth of the channel), and in cytosolic loops that link these 2 regions. This suggests that the PNDM mutations may provide clues to how ATP binding is translated into closure of the Kir6.2 pore. Two residues, V59 and R201, are mutated more commonly than others.

\section{A range of phenotypes}

Gain-of-function mutations in Kir6.2 cause a range of phenotypes, distinguished by increasing severity (Table 1). The most common class of mutation produces PNDM alone. These patients show minimal insulin secretion in response to i.v. glucose but may secrete insulin in response to sulfonylureas $(7,28,32,82,83)$. Other classes of mutation cause more severe phenotypes. Some patients have delayed speech and walking and may show muscle weakness in addition to neonatal diabetes $(7,29,30)$. A third class of mutations cause DEND syndrome, which is characterized by marked developmental delay, muscle weakness, epilepsy, dysmorphic features, and neonatal diabetes $(7,83-85)$. Mutations that cause less severe phenotypes than PNDM are also found. Thus, some mutations cause TNDM (33) and 1 mutation has been identified that causes diabetes of variable severity, ranging from TNDM to diabetes of adult onset (age 22-26) that resembles maturity-onset diabetes of the young (86).

\section{Functional effects of the mutations}

All PNDM mutations studied to date are gain-of-function mutations that act by reducing the ability of ATP to block the $\mathrm{K}_{\mathrm{ATP}}$ channel and thereby increasing the $\mathrm{K}_{\mathrm{ATP}}$ current amplitude under resting conditions $(7,33,83,84)$. There is a reasonable correlation between the clinical phenotype and the extent to which MgATP inhibition is reduced, when the heterozygous state is simulated in heterologous expression systems. Table 2 shows that, at physiologically relevant concentrations of $\operatorname{MgATP}(1-5 \mathrm{mM})$, mutations that cause small increases in $\mathrm{K}_{\mathrm{ATP}}$ current result in TNDM, while larger increases in current cause PNDM alone, and an even greater increase is associated with DEND syndrome. It will be important to determine whether this correlation between $\mathrm{K}_{\mathrm{ATP}}$ current and disease severity is a consistent feature.

In $\beta$ cells, an increase in $\mathrm{K}_{\mathrm{ATP}}$ current leads to a smaller depolarization in response to increased metabolism. Consequently, electrical activity and insulin secretion will be diminished, and the greater the increase in $\mathrm{K}_{\mathrm{ATP}}$ current, the more severely insulin secretion will be impaired. The $\beta$ cell may be especially sensitive to gain-of-function mutations in Kir6.2 as its resting potential is largely determined by the $\mathrm{K}_{\mathrm{ATP}}$ channel, and its metabolism is very sensitive to blood glucose levels.

Kir6.2 is also expressed in skeletal muscle, cardiac muscle, and neurons throughout the brain $(52,53)$, a distribution consistent with the neurological symptoms found in severe forms of the disease. Based on the functional data, it seems likely that in these tissues a greater reduction in ATP sensitivity is required to increase the $\mathrm{K}_{\mathrm{ATP}}$ current sufficiently to influence electrical activity. This might arise because $\mathrm{K}_{\mathrm{ATP}}$ channels contribute less to the electrical activity of these cells, perhaps because of a low density of $\mathrm{K}_{\mathrm{ATP}}$ channels; or because of contributions to membrane current from other ion channels; or because Kir6.2 associates with SUR2 (which may reduce the response to metabolism [ref. 22]); 
or because of differences in cell metabolism or other channel regulators. It is worth noting that $\mathrm{K}_{\mathrm{ATP}}$ channels are normally closed in many of these tissues and open only under conditions of metabolic stress $(25,27,87,88)$.

Precisely how severe mutations in Kir6.2 lead to epilepsy, developmental delay, muscle weakness, and dysmorphic features remains to be established, and sorting it out is likely to require animal models. At first sight, it appears paradoxical that epileptic symptoms can be caused by a gain-of-function mutation in a potassium channel. However, this is easily explained by overactivity of $\mathrm{K}_{\mathrm{ATP}}$ channels in inhibitory neurons, which would decrease inhibitory tone and enhance excitability of target neurons. Consistent with this idea, $\mathrm{K}_{\mathrm{ATP}}$ channels are expressed in most GABAergic inhibitory interneurons in the hippocampus, but only in a minority of excitatory pyramidal neurons (24); and diazoxide inhibits firing of interneurons but not pyramidal cells (25). Furthermore, $K_{\text {ATP }}$ channel openers prevent GABA release in slices of substantia nigra $(26,27)$. The muscle weakness could be of neural or muscle origin, as both skeletal muscle (53) and nerve terminals (89) express Kir6.2. Interestingly, the electrocardiogram of patients with PNDM mutations is superficially normal $(7,28)$, as observed for transgenic mice overexpressing a cardiac-targeted gain-of-function mutation in Kir6.2 (90).

Although gain-of-function Kir6.2 mutations cause epilepsy in humans, transgenic mice overexpressing WT Kir6.2 or SUR1 in forebrain are protected against seizure and ischemic injury (15, 16), and knockout of Kir6.2 enhances susceptibility to generalized seizure (14). This suggests that $\mathrm{K}_{\mathrm{ATP}}$ current magnitude may be critical for brain function, and that too little current as well as too much can predispose to seizure: this might reflect the relative amounts of $\mathrm{K}_{\mathrm{ATP}}$ current in inhibitory and excitatory neurons. Alternatively, the transgenic mice may not provide a perfect model of the human disease.

\section{Molecular basis of reduced ATP sensitivity}

As discussed above, ATP has 2 effects on the $\mathrm{K}_{\text {ATP }}$ channel: ATP binding to Kir6.2, in a process that does not require $\mathrm{Mg}^{2+}$, blocks the channel, whereas binding of MgATP to SUR1 stimulates channel activity (49). It is therefore essential to analyze the molecular mechanism of ATP block both in $\mathrm{Mg}^{2+}$-free solution (to avoid the complicating effects of MgATP stimulation), and in the presence of $\mathrm{Mg}^{2+}$ to determine whether coupling of SUR1 to Kir6.2 is affected.

Studies in Mg-free solution have shown that although all PNDM mutations reduce the ability of ATP to block the $\mathrm{K}_{\text {ATP }}$ channel, they do so by a variety of molecular mechanisms $(83,84)$. To date, mutations that cause neonatal diabetes alone (e.g., R201H/C, I182V) impair ATP binding directly $(7,33,83,91)$, consistent with their location within the predicted ATP-binding site (Figures 3 and 4). In contrast, mutations that cause DEND syndrome (e.g., V59G, Q52R, I296L) affect ATP inhibition indirectly. They bias the channel toward the open state and impair its ability to close $(83,84)$ (Figure 5). Consequently, the fraction of time the channel spends open in the absence of ATP (the intrinsic open probability, Po) is increased. Because the affinity of the open state for ATP is less than that of the closed state, mutant channels are less inhibited by ATP (92). These mutations lie in regions predicted to be involved in channel gating (Figure 3). Finally, some mutations (V59G, I296L) appear to influence both intrinsic gating and ATP binding (or the mechanism by which binding is translated into channel closure) $(83,84)$.
In the presence of $\mathrm{Mg}^{2+}$, the ATP sensitivity of the channel is reduced (49). This effect appears to be greater for several PNDM mutant channels $(33,84)$, suggesting that MgATP activation via SUR1 may be enhanced. However, studies to date are limited, and this area requires more work.

\section{The importance of heterozygosity}

All PNDM patients identified to date are heterozygotes. Because Kir6.2 is a tetramer $(50,51)$, their cells will express a mixed pop-
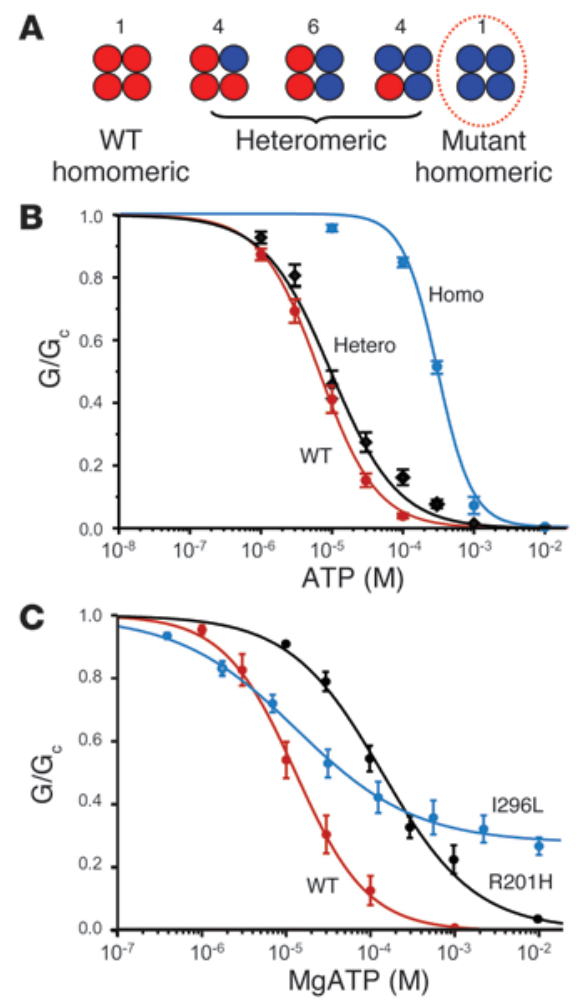

\section{Figure 4}

PNDM mutations reduce channel inhibition by ATP. (A) Schematic of the mixture of channels with different subunit compositions expected when WT and mutant Kir6.2 are coexpressed (as in the heterozygous state). The relative numbers of the channel types expected if WT and mutant subunits segregate independently (i.e., follow a binomial distribution) are indicated above the figure. The circle indicates the only channel type predicted to show a substantial change in ATP sensitivity if the mutation affects ATP binding (see text). (B) Mean relationship between [ATP] and $\mathrm{K}_{\text {ATP }}$ current $(\mathrm{G})$, expressed relative to the conductance in the absence of nucleotide $\left(\mathrm{G}_{\mathrm{C}}\right)$ for Kir6.2/SUR1 (red, $n=6$ ) and heterozygous (black, $n=6$ ) and homomeric (blue, $n=6$ ) Kir6.2R201H/SUR1 channels. The smooth curves are the best fit to the Hill equation. The $\mathrm{IC}_{50}$ was $7 \mu \mathrm{M}, 12 \mu \mathrm{M}$, and $300 \mu \mathrm{M}$ for $\mathrm{WT}$, heterozygous $\mathrm{R} 201 \mathrm{H}$, and homomeric $\mathrm{R} 201 \mathrm{H}$ channels, respectively. Data were obtained in the absence of $\mathrm{Mg}^{2+}$. Part $\mathrm{B}$ reproduced with permission from Proceedings of the National Academy of Sciences of the United States of America (83). (C) Mean relationship between [MgATP] and $\mathrm{K}_{\mathrm{ATP}}$ current, expressed relative to the conductance in the absence of nucleotide for Kir6.2/SUR1 (red, $n=6$ ) and heterozygous Kir6.2R201H (black, $n=5$ ) and heterozygous Kir6.2-I296L/SUR1 (blue, $n=5$ ) channels. The smooth curves are the best fit to the Hill equation. The $\mathrm{IC}_{50}$ was $13 \mu \mathrm{M}, 140 \mu \mathrm{M}$, and $50 \mu \mathrm{M}$ for WT, heterozygous $\mathrm{R} 201 \mathrm{H}$, and heterozygous $\mathrm{I296L}$ channels, respectively. Data in C are from refs. 33 and 84. 
A

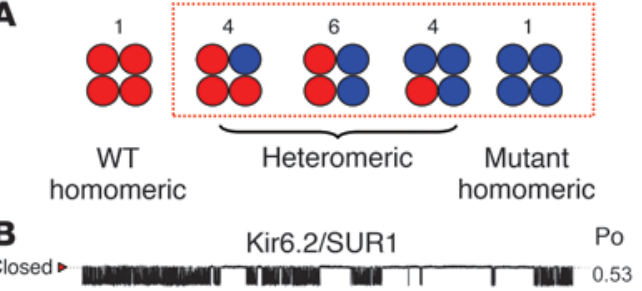

Kir6.2-R201C/SUR1

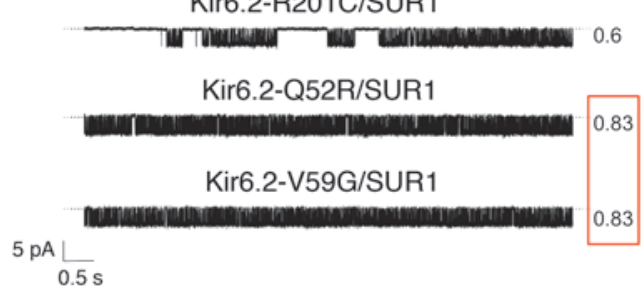

$0.5 \mathrm{~s}$

Figure 5

Effects of Kir6.2 mutations on channel gating. (A) Schematic of the different channel types expected when WT and mutant Kir6.2 are coexpressed (as in the heterozygous state). The box indicates channel types expected to have altered ATP sensitivity if the mutation affects channel gating (see text). (B) Single $K_{\text {ATP }}$ channel currents recorded at $-60 \mathrm{mV}$ from inside-out patches from oocytes coinjected with mRNAs encoding SUR1 plus either WT or mutant Kir6.2 as indicated. Reproduced with permission from Proceedings of the National Academy of Sciences of the United States of America (83).

ulation of channels, each containing between 0 and 4 mutant subunits (Figure 4A). The ATP sensitivity of each of these 5 channel types will be determined by the extent to which each subunit (WT or mutant) contributes to the overall ATP sensitivity, and by the number of mutant subunits. In turn, the contribution of the mutant subunit will depend on whether it primarily affects ATP binding or intrinsic gating. For this reason, it is essential to study the effect of a mutation on the heterozygous channel population, whose behavior is not easily predicted from studies of homomeric mutant channels.

Because binding of a single ATP molecule closes the $\mathrm{K}_{\mathrm{ATP}}$ channel (93), a mutation that reduces ATP binding will substantially impair ATP block only when all 4 subunits are mutant. If WT and mutant Kir6.2 subunits distribute randomly $(51,93)$, only onesixteenth of channels in the heterozygous population will contain 4 mutant subunits (Figure 4). Thus the shift in the ATP sensitivity of the mean channel population will be small, precisely as seen for heterozygous R201C and R201H channels $(7,33,83)$.

Mutations that affect intrinsic gating cause larger shifts in the ATP sensitivity of the heterozygous channel population. This can be explained if the energy of the open state scales with the number of mutant subunits (83); in this case, the ATP sensitivity of more than $90 \%$ of channels in the heterozygous population will be affected (Figure 5A). This explains why mutations that affect the intrinsic Po (such as Q52R, V59G, and I296L) cause a greater shift in the ATP sensitivity of heterozygous channels. The ATP sensitivity of heterozygous Q52R channels is well fit by assuming that the entire shift in ATP sensitivity results from the observed change in channel gating (83). However, other mutations (V5G, I296L) cause even greater shifts in the ATP sensitivity of both homomeric and heterozygous channels and appear to have additional effects on ATP binding and/or transduction $(83,84)$.
The importance of heterozygosity in determining the severity of a mutation appears to be a novel feature of gain-of-function $\mathrm{K}_{\mathrm{ATP}}$ channelopathies. Accordingly, we may expect to find similar phenotypic variability in other tetrameric ion channels where channel function can be influenced differentially by the presence of 1 , or more, mutant subunits. It is also worth noting that if mutant and WT subunits were to express at different levels, the composition of the heterozygous population might deviate from a binomial distribution and thus influence the channel ATP sensitivity in a less quantitatively predictable fashion.

\section{Implications for therapy}

Prior to the discovery that PNDM could be caused by mutations in Kir6.2, it was supposed that patients with this disorder suffered from early-onset, type 1 diabetes, and they were treated with insulin. Recent studies, however, demonstrate that patients with mutations that cause PNDM alone can be managed on sulfonylureas (7, 28,82 ). It remains to be seen whether sulfonylurea therapy is effective in the long term. However, it is important to remember that while insulin therapy may control the diabetes, it does not mitigate the effects of enhanced $\mathrm{K}_{\mathrm{ATP}}$ channel activity in nonpancreatic tissue: this requires drugs that close $\mathrm{K}_{\text {ATP }}$ channels. Whether sulfonylurea therapy will be as suitable for patients with mutations that increase the intrinsic Po of the channel remains unclear, because these channels are less sensitive to the drugs (83). This is expected, as mutations that stabilize the channel in the open state impair sulfonylurea inhibition (92). However, it may be possible to manage such patients, on a combination of insulin, to control their diabetes, and sulfonylureas, to control the extrapancreatic effects. A key question is whether sulfonylureas will be effective at treating CNS symptoms, as the extent to which they cross the blood/brain barrier is unclear. Drugs that enter the brain and selectively block $\mathrm{K}_{\mathrm{ATP}}$ channels might be beneficial in this respect.

The efficacy of sulfonylurea therapy in PNDM will also depend on the particular gene that is mutated. Loss-of-function mutations in metabolic genes, such as GCK, reduce ATP production and enhance $\mathrm{K}_{\text {ATP }}$ channel activity indirectly. Blocking the $\mathrm{K}_{\mathrm{ATP}}$ channel with sulfonylureas will restore $\mathrm{Ca}^{2+}$ influx but, as ATP is also required for the secretory process, may not be sufficient to reinstate insulin secretion fully.

\section{Impaired metabolic regulation and early-onset diabetes}

Impaired metabolic regulation of $\mathrm{K}_{\mathrm{ATP}}$ channels, resulting from mutations in genes that influence $\beta$ cell metabolism, can cause both monogenic $\mathrm{HI}$ and diabetes. As described above, mutations in GCK and GLUD1 cause HI, probably by enhancing metabolic ATP generation and decreasing $\mathrm{K}_{\mathrm{ATP}}$ channel activity. Conversely, mutations that reduce ATP synthesis, and thus the extent of $\mathrm{K}_{\mathrm{ATP}}$ channel inhibition in response to glucose metabolism, may be expected to give rise to diabetes.

Maturity-onset diabetes of the young (MODY) is characterized by early onset, autosomal dominant inheritance, and pancreatic $\beta$ cell dysfunction $(66,94)$. It is caused by mutations in at least 7 different genes. Heterozygous loss-of-function mutations in GCK cause MODY2, which is associated with moderate hyperglycemia and is often asymptomatic and detected only during routine screening: as described above, homozygous inactivating mutations in GCK impair $\beta$ cell metabolism more severely and cause permanent neonatal diabetes. Five other MODY genes encode the transcription factors HNF $4 \alpha, H N F 1 \alpha$, IPF1, HNF1 $\beta$, and NEUROD, 
which are not only important for $\beta$ cell development but can also regulate expression of genes critical for glucose metabolism. For example, knockout of HNF1 $\alpha$, which causes MODY3, impairs $\beta$ cell glucose metabolism and thereby $\mathrm{K}_{\mathrm{ATP}}$ channel closure in mice (95). Whether other transcription factors influence $\mathrm{K}_{\mathrm{ATP}}$ channel function has yet to be established. Finally, as described above, mutations in Kir6.2 itself can also give rise to MODY (86).

Defective mitochondrial metabolism can also produce diabetes, as in maternally inherited diabetes with deafness (MIDD), which results from a mutation in the mitochondrial DNA that encodes a leucine transfer RNA $(96,97)$. It seems plausible to speculate that enhanced $\mathrm{K}_{\mathrm{ATP}}$ channel activity, due to reduced ATP production, contributes to the impaired insulin secretion.

\section{Implications for type 2 diabetes}

Given that mutations in Kir6.2 cause neonatal diabetes and MODY, and that mutations in genes that regulate $\mathrm{K}_{\mathrm{ATP}}$ channel activity lead to MODY and MIDD, which present in childhood or early adult life, it is natural to conjecture that common genetic variations in the same genes, which produce smaller functional effects, might predispose to type 2 diabetes in later life. Accumulating evidence supports this view.

Large-scale association studies indicate that a common variant (E23K) in Kir6.2 is strongly associated with an enhanced susceptibility to type 2 diabetes (98-100). Although the effect is statistically small (the odds ratio associated with the K allele is only $\sim 1.2$ ), the high prevalence of the Kallele (34\%) makes this a significant population risk. Precisely how the E23K polymorphism enhances diabetes susceptibility remains unclear. Data obtained by expressing recombinant $\mathrm{K}_{\mathrm{ATP}}$ channels in heterologous systems are conflicting. Some studies demonstrate an increase in intrinsic Po, with a consequent reduction in ATP sensitivity, and enhanced activation by $\mathrm{Mg}$ nucleotides $(101,102)$, whereas others report no effect on ATP sensitivity but enhanced sensitivity to the stimulatory action of long-chain acyl-CoAs (103). It is also possible that the E23K variant may cause a greater reduction in ATP block of the $\mathrm{K}_{\mathrm{ATP}}$ channel in pancreatic $\beta$ cells than in heterologous systems. Interestingly, in mice, a 4-fold reduction in $\mathrm{K}_{\mathrm{ATP}}$ channel ATP sensitivity is enough to cause neonatal diabetes (3). Furthermore, large-scale studies in humans have shown that the $\mathrm{E} 23 \mathrm{~K}$ variant is associated with reduced insulin secretion in glucose-tolerant subjects $(104,105)$. It is also worth remembering that because Kir6.2 is expressed in multiple tissues, diabetes susceptibility may involve tissues other than the $\beta$ cell: for example, glucagon secretion is increased in individuals carrying $2 \mathrm{~K}$ alleles (106).

Polymorphisms in HNF1 $\alpha$, HNF4 $\alpha$, and GCK (107-109), and in genes involved in mitochondrial metabolism $(110,111)$, have also been associated with an increased risk of type 2 diabetes. They probably influence disease susceptibility by impairing metabolic regulation of $\mathrm{K}_{\mathrm{ATP}}$ channel activity.

This leads to the conclusion that good candidate genes for polygenic disease (in this case, type 2 diabetes) are those that cause monogenic disease (PNDM, MODY). As they manifest only in later life, the functional effects of individual gene variants associated with polygenic disease are likely to be small. It also suggests that the increased risk of diabetes with age may reflect a deteriorating $\beta$ cell metabolism, leading to enhanced $K_{\text {ATP }}$ channel activity and reduced insulin secretion (62). This idea is supported by the fact that insulin secretion is critically dependent on mitochondrial metabolism (112), which is known to decline with age (113) and has been implicated in age-related disease (112-114).

\section{Conclusions}

$\mathrm{K}_{\mathrm{ATP}}$ channel activity in the $\beta$ cell is finely balanced, reflecting its physiological role as a key regulator of insulin release. Increased activity leads to reduced insulin secretion, and, conversely, reduced $\mathrm{K}_{\mathrm{ATP}}$ channel activity decreases insulin release. Consequently, mutations that either directly or indirectly alter $\beta$ cell $\mathrm{K}_{\mathrm{ATP}}$ channel activity produce a spectrum of diseases that ranges from severe HI to DEND syndrome (Figure 6).

In general, there is a good correlation between the magnitude of the $K_{\text {ATP }}$ current and disease severity. Thus mutations that cause a total loss of $\mathrm{K}_{\mathrm{ATP}}$ channel in the surface membrane produce severe HI, whereas those that impair channel function only partially produce a milder phenotype that can be treated with diazoxide or results in leucine-sensitive HI. Likewise, the extent to which the ATP sensitivity of Kir6.2 is decreased determines the severity of the diabetes phenotype. Mutations that cause the greatest reduction in ATP inhibition, and the largest increase in $\mathrm{K}_{\mathrm{ATP}}$ channel activity, manifest effects in multiple tissues and lead to developmental delay, epilepsy, muscle weakness, and neonatal diabetes. Lesser shifts in ATP sensitivity give rise to neonatal diabetes with developmental delay, while even smaller changes manifest primarily in the $\beta$ cell and cause neonatal diabetes alone.

The range of phenotypes associated with monogenic $\mathrm{K}_{\mathrm{ATP}}$ channelopathies, which present at birth, suggests a similar spectrum

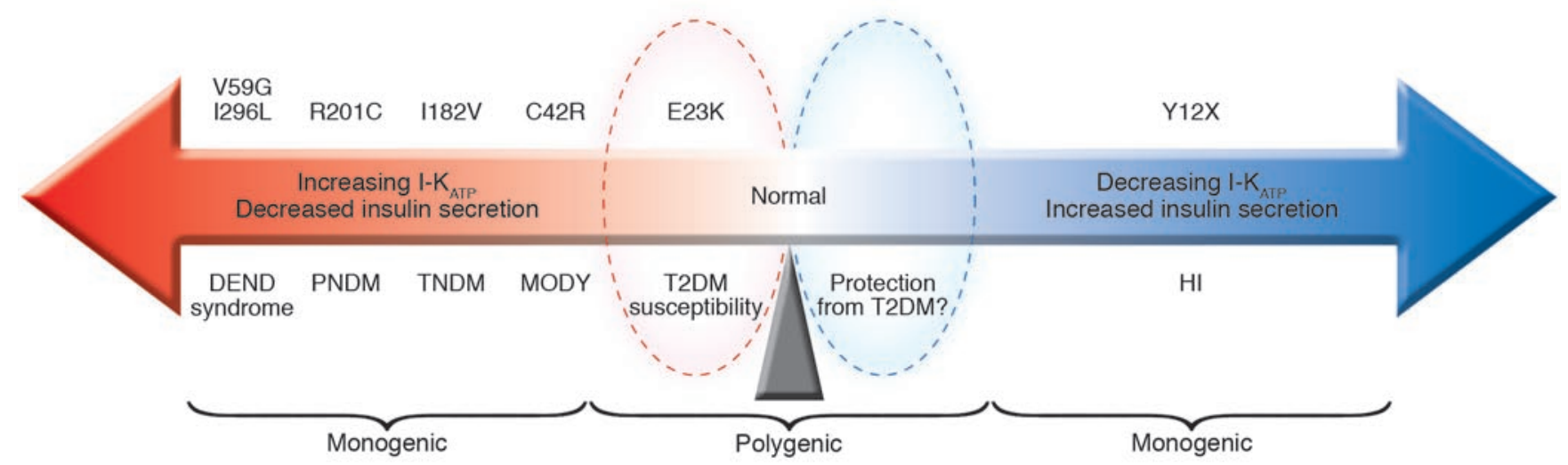

Figure 6

Schematic illustrating the relationship between $\mathrm{K}_{\text {ATP }}$ channel activity and insulin secretion. T2DM, type 2 diabetes mellitus. 
of $\mathrm{K}_{\mathrm{ATP}}$ channel polymorphisms that have less severe effects on channel function and predispose to late-onset, polygenic, disease. The association of the E23K polymorphism in Kir6.2 with susceptibility to type 2 diabetes supports this idea. Because of a gradual decline in $\beta$ cell function with age, polymorphisms that cause a small decrease in $\mathrm{K}_{\mathrm{ATP}}$ channel activity are unlikely to predispose to late development of HI but rather may help to protect against type 2 diabetes.

It is noteworthy that mutations in Kir6.2 cause both diabetes and HI, whereas mutations in SUR1 are, to date, entirely associated with hyperinsulinism. This is not unexpected, however. A total loss of protein (Kir6.2 or SUR1) will necessarily result in loss of $\mathrm{K}_{\mathrm{ATP}}$ channel activity and thus $\mathrm{HI}$. Loss of metabolic regulation, however, will have different effects in Kir6.2 and SUR1. For SUR1, impaired binding/hydrolysis and/or transduction of $\mathrm{Mg}$ nucleotides will decrease $\mathrm{K}_{\mathrm{ATP}}$ channel activity, producing HI. Mutations that enhance $\mathrm{Mg}$-nucleotide activation seem inherently far less likely. Thus, diabetes due to SUR1 mutations will be rare. Mutations that impair ATP binding to Kir6.2, on the other hand, will enhance $\mathrm{K}_{\mathrm{ATP}}$ channel activity and cause diabetes. It is not understood why mutations that affect Kir6.2 gating invariably increase channel opening (thereby lowering ATP sensitivity), but this may suggest that the channel is most stable in the open state.

Finally, a similar spectrum of insulin secretory disorders can be expected from mutations in genes that regulate $\mathrm{K}_{\mathrm{ATP}}$ channel activity, with mutations that indirectly enhance $\mathrm{K}_{\mathrm{ATP}}$ currents mediating diabetes and those that reduce channel activity producing HI. As expected, loss-of-function mutations in metabolic genes cause
PNDM or MODY depending on the extent to which they impair $\beta$ cell metabolism, while gain-of-function mutations cause HI of varying severity. Naturally occurring polymorphisms in genes that cause minor variations in metabolic regulation, or density, of $\mathrm{K}_{\mathrm{ATP}}$ channels can be predicted to produce small differences in $\mathrm{K}_{\mathrm{ATP}}$ channel activity and insulin secretion, so influencing diabetes susceptibility. Some such polymorphisms have been identified, and more are likely to follow.

In conclusion, individuals may be predisposed to either $\mathrm{HI}$ or diabetes according to the magnitude of their $\beta$ cell $\mathrm{K}_{\mathrm{ATP}}$ current under resting conditions, with their position on this delicate $K_{A T P}$ channel see-saw being determined by their unique combination of polymorphisms in multiple genes.

\section{Acknowledgments}

The author wishes to thank those working in the field who have contributed greatly to the ideas expressed in this review, especially Jennifer Antcliff, Christophe Girard, Peter Proks, and Paolo Tammaro in the author's group, and colleagues Roger Cox, Anna Gloyn, Fiona Gribble, Andrew Hattersley, and Patrik Rorsman. The author also thanks the Wellcome Trust, Diabetes UK, GrowBeta, and the Royal Society for support. F.M. Ashcroft is the Royal Society GlaxoSmithKline Research Professor.

Address correspondence to: Frances Ashcroft, University Laboratory of Physiology, Parks Road, Oxford OX1 3PT, United Kingdom. Phone: 01865-285810; Fax: 01865-285813; E-mail: frances. ashcroft@physiol.ox.ac.uk.
1. Seino, S., and Miki, T. 2004. Gene targeting approach to clarification of ion channel function: studies of Kir6.x null mice. J. Physiol. 554:295-300.

2. Ashcroft, F.M., Harrison, D.E., and Ashcroft, S.J.H. 1984. Glucose induces closure of single potassium channels in isolated rat pancreatic $\beta$-cells. Nature. 312:446-448

3. Koster, J.C., Marshall, B.A., Ensor, N., Corbett, J.A., and Nichols, C.G. 2000. Targeted overactivity of beta cell K(ATP) channels induces profound neonatal diabetes. Cell. 100:645-654.

4. Miki, T., et al. 1998. Defective insulin secretion and enhanced insulin action in $\mathrm{K}_{\mathrm{ATP}}$ channel-deficient mice. Proc. Natl. Acad. Sci. U. S. A. 95:10402-10406.

5. Seghers, V., Nakazaki, M., DeMayo, F., AguilarBryan, L., and Bryan, J. 2000. Sur1 knockout mice. A model for K(ATP) channel-independent regulation of insulin secretion. J. Biol. Chem. 275:9270-9277.

6. Dunne, M.J., Cosgrove, K.E., Shepherd, R.M., Aynsley-Green, A., and Lindley, K.J. 2004. Hyperinsulinism in infancy: from basic science to clinical disease. Physiol. Rev. 84:239-275.

7. Gloyn, A.L., et al. 2004. Activating mutations in the ATP-sensitive potassium channel subunit Kir6.2 gene are associated with permanent neonatal diabetes. N. Engl. J. Med. 350:1838-1849.

8. Gopel, S.O., et al. 2000. Regulation of glucagon release in mouse alpha-cells by $\mathrm{K}_{\mathrm{ATP}}$ channels and inactivation of TTX-sensitive $\mathrm{Na}^{+}$channels. J. Physiol. 528:509-520.

9. Gopel, S.O., Kanno, T., Barg, S., and Rorsman, P. 2000. Patch-clamp characterisation of somatostatin-secreting $\delta$-cells in intact mouse pancreatic islets. J. Physiol. 528:497-507.

10. Gribble, F.M., Williams, L., Simpson, A.K., and Reimann, F. 2003. A novel glucose-sensing mechanism contributing to glucagon-like peptide- 1 secretion from the GLUTag cell line. Diabetes. 52:1147-1154.

11. Miki, T., et al. 2001. ATP-sensitive $\mathrm{K}^{+}$channels in the hypothalamus are essential for the maintenance of glucose homeostasis. Nat. Neurosci. 4:507-512.
12. Wang, R., et al. 2004. The regulation of glucoseexcited neurons in the hypothalamic arcuate nucleus by glucose and feeding-relevant peptides. Diabetes. 53:1959-1965.

13. Zingman, L.V., et al. 2002. Kir6.2 is required for adaptation to stress. Proc. Natl Acad. Sci. U. S. A. 99:13278-13283.

14. Yamada, K., et al. 2001. Protective role of ATP-sensitive potassium channels in hypoxia-induced generalized seizure. Science. 292:1543-1546.

15. Hernandez-Sanchez, C., et al. 2001. Mice transgenically overexpressing sulfonylurea receptor 1 in forebrain resist seizure induction and excitotoxic neuron death. Proc. Natl Acad. Sci. U. S. A. 98:3549-3554.

16. Heron-Milhavet, L., et al. 2004. Protection against hypoxic-ischemic injury in transgenic mice overexpressing Kir6.2 channel pore in forebrain. Mol. Cell. Neurosci. 25:585-593.

17. Suzuki, M., et al. 2002. Role of sarcolemmal $\mathrm{K}_{\mathrm{ATP}}$ channels in cardioprotection against ischemia/reperfusion injury in mice. J. Clin. Invest. 109:509-516. doi:10.1172/JCI200214270.

18. Gumina, R.J., et al. 2003. Knockout of Kir6.2 negates ischemic preconditioning-induced protection of myocardial energetics. Am. J. Physiol. Heart Circ. Physiol. 284:H2106-H2113.

19. Daut, J., Klieber, H.G., Cyrys, S., and Noack, T. 1994. K $\mathrm{K}_{\mathrm{ATP}}$ channels and basal coronary vascular tone. Cardiovasc. Res. 28:811-817.

20. Miki, T., et al. 2002. Mouse model of Prinzmetal angina by disruption of the inward rectifier Kir6.1. Nat. Med. 8:466-472.

21. Chutkow, W.A., et al. 2002. Episodic coronary artery vasospasm and hypertension develop in the absence of Sur2 $\mathrm{K}_{\mathrm{ATP}}$ channels. J. Clin. Invest. 110:203-208. doi:10.1172/JCI200215672.

22. Liss, B., Bruns, R., and Roeper, J. 1999. Alternative sulfonylurea receptor expression defines metabolic sensitivity of $\mathrm{K}_{\mathrm{ATP}}$ channels in dopaminergic midbrain neurons. EMBO J. 18:833-846.

23. Avshalumov, M.V., and Rice, M.E. 2003. Activa- tion of ATP-sensitive $\mathrm{K}^{+}\left(\mathrm{K}_{\text {ATP }}\right)$ channels by $\mathrm{H}_{2} \mathrm{O}_{2}$ underlies glutamate-dependent inhibition of striatal dopamine release. Proc. Natl. Acad. Sci. U. S. A. 100:11729-11734.

24. Zawar, C., Plant, T.D., Schirra, C., Konnerth, A., and Neumcke, B. 1999. Cell-type specific expression of ATP-sensitive potassium channels in the rat hippocampus. J. Physiol. 514:327-341.

25. Griesemer, D., Zawar, C., and Neumcke, B. 2002. Cell-type specific depression of neuronal excitability in rat hippocampus by activation of ATP-sensitive potassium channels. Eur. Biophys. J. 31:467-477.

26. Schmid-Antomarchi, H., Amoroso, S., Fosset, M., and Lazdunski, M. 1990. $\mathrm{K}^{+}$channel openers activate brain sulfonylurea-sensitive $\mathrm{K}^{+}$channels and block neurosecretion. Proc. Natl. Acad. Sci. U. S. A. 87:3489-3492.

27. Amoroso, S., Schmid-Antomarchi, H., Fosset, M., and Lazdunski, M. 1990. Glucose, sulfonylureas, and neurotransmitter release: role of ATP-sensitive $\mathrm{K}^{+}$channels. Science. 247:852-854.

28. Sagen, J.V., et al. 2004. Permanent neonatal diabetes due to mutations in KCNJ11 encoding Kir6.2: patient characteristics and initial response to sulfonylurea therapy. Diabetes. 53:2713-2718.

29. Vaxillaire, M., et al. 2004. Kir6.2 mutations are a common cause of permanent neonatal diabetes mellitus in a large cohort of French patients. Diabetes. 53:2719-2722.

30. Massa, O., et al. 2005. KCNJ11 activating mutations in Italian patients with permanent neonatal diabetes. Hum. Mutat. 25:22-27.

31. Gloyn, A.L., et al. 2004. Permanent neonatal diabetes due to paternal germline mosaicism for an activating mutation of the KCNJ11 gene encoding the Kir6.2 subunit of the beta-cell potassium adenosine triphosphate channel. J. Clin. Endocrinol. Metab. 89:3932-3935.

32. Edghill, E.L., et al. 2004. Activating mutations in the KCNJ11 gene encoding the ATP-sensitive $\mathrm{K}^{+}$ channel subunit Kir6.2 are rare in clinically defined 
type 1 diabetes diagnosed before 2 years. Diabetes. 53:2998-3001.

33. Gloyn, A.L., et al. 2005. Relapsing diabetes can result from moderately activating mutations in KCNJ11. Hum. Mol. Genet. 14:925-934.

34. Glaser, B., Thornton, P., Otonkoski, T., and Junien, C. 2000. Genetics of neonatal hyperinsulinism. Arch. Dis. Child. Fetal Neonatal Ed. 82:F79-F86.

35. Thomas, P.M., et al. 1995. Mutations in the sulfonylurea receptor gene in familial persistent hyperinsulinemic hypoglycemia of infancy. Science. 268:426-429.

36. Nestorowicz, A., et al. 1997. A nonsense mutation in the inward rectifier potassium channel gene, Kir6.2, is associated with familial hyperinsulinism. Diabetes. 46:1743-1748.

37. Thomas, P., Ye, Y., and Lightner, E. 1996. Mutation of the pancreatic islet inward rectifier Kir6.2 also leads to familial persistent hyperinsulinemic hypoglycemia of infancy. Hum. Mol. Genet. 5:1809-1812.

38. Henwood, M.J., et al. 2005. Genotype-phenotype correlations in children with congenital hyperinsulinism due to recessive mutations of the adenosine triphosphate-sensitive potassium channel genes. J. Clin. Endocrinol. Metab. 90:789-794.

39. Huopio, H., et al. 2000. Dominantly inherited hyperinsulinism caused by a mutation in the sulfonylurea receptor type 1. J. Clin. Invest. 106:897-906.

40. Magge, S.N., et al. 2004. Familial leucine-sensitive hypoglycemia of infancy due to a dominant mutation of the beta-cell sulfonylurea receptor. J. Clin. Endocrinol. Metab. 89:4450-4456.

41. Bienengraeber, M., et al. 2004. ABCC9 mutations identified in human dilated cardiomyopathy disrupt catalytic KATP channel gating. Nat. Genet. 36:382-387.

42. Ashcroft, F.M., and Rorsman, P. 1989. Electrophysiology of the pancreatic $\beta$-cell. Prog. Biophys. Mol. Biol. 54:87-143.

43. Henquin, J.C. 2000. Triggering and amplifying pathways of regulation of insulin secretion by glucose. Diabetes. 49:1751-1760.

44. Gribble, F.M., and Reimann, F. 2003. Sulphonylurea action revisited: the post-cloning era. Diabetologia. 46:875-891

45. Gribble, F., and Ashcroft, F.M. 2000. New windows on the mechanism of action of potassium channel openers [review]. Trends Pharmacol. Sci. 21:439-445.

46. Bokvist, K., et al. 1991. Separate processes mediate nucleotide-induced inhibition and stimulation of the ATP-regulated $\mathrm{K}(+)$-channels in mouse pancreatic beta-cells. Proc. R. Soc. Lond., B, Biol. Sci. 243:139-144.

47. Hopkins, W.F., Fatherazi, S., Peter-Riesch, B., Corkey, B.E., and Cook, D.L. 1992. Two sites for adenine-nucleotide regulation of ATP-sensitive potassium channels in mouse pancreatic beta-cells and HIT cells. J. Membr. Biol. 129:287-295.

48. Tucker, S.J., Gribble, F.M., Zhao, C., Trapp, S., and Ashcroft, F.M. 1997. Truncation of Kir6.2 produces ATP-sensitive $\mathrm{K}^{+}$channels in the absence of the sulphonylurea receptor. Nature. 387:179-183.

49. Gribble, F.M., Tucker, S.J., Haug, T., and Ashcroft, F.M. 1998. MgATP activates the $\beta$-cell $K_{\text {ATP }}$ channel by interaction with its SUR1 subunit. Proc. Natl. Acad. Sci. U. S. A. 95:7185-7190.

50. Clement, J.P., 4th, et al. 1997. Association and stoichiometry of $\mathrm{K}_{\mathrm{ATP}}$ channel subunits. Neuron. 18:827-838.

51. Shyng, S.L., and Nichols, C.G. 1997. Octameric stoichiometry of the $\mathrm{K}_{\mathrm{ATP}}$ channel complex. J. Gen. Physiol. 110:655-664.

52. Inagaki, N., et al. 1995. Reconstitution of $\mathrm{I}_{\text {KATP: }}$ an inward rectifier subunit plus the sulfonylurea receptor. Science. 270:1166-1169.

53. Sakura, H., Ammala, C., Smith, P.A., Gribble, F.M., and Ashcroft, F.M. 1995. Cloning and functional expression of the cDNA encoding a novel ATP- sensitive potassium channel subunit expressed in pancreatic $\beta$-cells, brain, heart and skeletal muscle. FEBS Lett. 377:338-344.

54. Inagaki, N., et al. 1995. Cloning and functional characterization of a novel ATP-sensitive potassium channel ubiquitously expressed in rat tissues, including pancreatic islets, pituitary, skeletal muscle, and heart. J. Biol. Chem. 270:5691-5694.

55. Tanabe, K., et al. 1999. Direct photoaffinity labeling of the Kir6.2 subunit of the ATP-sensitive $\mathrm{K}^{+}$channel by 8-azido-ATP. J. Biol. Chem. 274:3931-3933.

56. Aguilar-Bryan, L., et al. 1995 . Cloning of the $\beta$-cell high-affinity sulfonylurea receptor: a regulator of insulin secretion. Science. 268:423-426.

57. Nichols, C.G., et al. 1996. Adenosine diphosphate as an intracellular regulator of insulin secretion. Science. 272:1785-1787.

58. Gribble, F.M., Tucker, S.J., and Ashcroft, F.M. 1997. The essential role of the Walker A motifs of SUR1 in $\mathrm{K}_{\mathrm{ATP}}$ channel activation by MgADP and diazoxide. $E M B O J .16: 1145-1152$.

59. Chutkow, W.A., Simon, M.C., Beau, M.M.L., and Burant, C.F. 1996. Coning, tissue expression, and chromosomal localization of SUR2, the putative drug-binding subunit of cardiac, skeletal muscle, and vascular $\mathrm{K}_{\mathrm{ATP}}$ channels. Diabetes. 45:1439-1445.

60. Inagaki, N., et al. 1996. A family of sulfonylurea receptors determines the pharmacological properties of ATP-sensitive $\mathrm{K}^{+}$channels. Neuron. 16:1011-1017.

61. Isomoto, S., et al. 1996. A novel sulfonylurea receptor forms with BIR (Kir6.2) a smooth muscle type ATP-sensitive $\mathrm{K}^{+}$channel. J. Biol. Chem. 271:24321-24324.

62. Ashcroft, F.M., and Rorsman, P. 2004. Type-2 diabetes mellitus: not quite exciting enough? Hum. Mol. Genet. 13:R21-R31.

63. Kanno, T., Rorsman, P., and Gopel, S.O. 2002. Glucose-dependent regulation of rhythmic action potential firing in pancreatic beta-cells by $\mathrm{K}_{(\mathrm{ATP})}$ channel modulation. J. Physiol. 545:501-507.

64. Smith, P.A., et al. 1997. Electrogenic arginine transport mediates stimulus-secretion coupling in mouse pancreatic $\beta$-cells. J. Physiol. 499:625-635.

65. Rolland, J.F., Henquin, J.C., and Gilon, P. 2002. G protein-independent activation of an inward $\mathrm{Na}(+)$ current by muscarinic receptors in mouse pancreatic beta-cells. J. Biol. Chem. 277:38373-38380.

66. Gloyn, A.L. 2003. Glucokinase (GCK) mutations in hyper- and hypoglycemia: maturity-onset diabetes of the young, permanent neonatal diabetes, and hyperinsulinemia of infancy. Hum. Mutat. 22:353-362.

67. Glaser, B., et al. 1998. Familial hyperinsulinism caused by an activating glucokinase mutation. N. Engl. J. Med. 338:226-230

68. Stanley, C.A., et al. 1998. Hyperinsulinism and hyperammonemia in infants with regulatory mutations of the glutamate dehydrogenase gene. N. Engl. J. Med. 338:1352-1357.

69. Molven, A., et al. 2004. Familial hyperinsulinemic hypoglycemia caused by a defect in the SCHAD enzyme of mitochondrial fatty acid oxidation. Diabetes. 53:221-227.

70. Taschenberger, G., et al. 2002. Identification of a familial hyperinsulinism-causing mutation in the sulfonylurea receptor 1 that prevents normal trafficking and function of $\mathrm{K}_{\mathrm{ATP}}$ channels. J. Biol. Chem. 277:17139-17146.

71. Partridge, C.J., Beech, D.J., and Sivaprasadarao, A. 2001. Identification and pharmacological correction of a membrane trafficking defect associated with a mutation in the sulfonylurea receptor causing familial hyperinsulinism. J. Biol. Chem. 276:35947-35952.

72. Yan, F., et al. 2004. Sulfonylureas correct trafficking defects of ATP-sensitive potassium channels caused by mutations in the sulfonylurea receptor. J. Biol. Chem. 279:11096-11105.
73. Zerangue, N., Schwappach, B., Jan, Y.N., and Jan, L.Y. 1999. A new ER trafficking signal regulates the subunit stoichiometry of plasma membrane K(ATP) channels. Neuron. 22:537-548.

74. Cuesta-Munoz, A.L., et al. 2004. Severe persistent hyperinsulinemic hypoglycemia due to a de novo glucokinase mutation. Diabetes. 53:2164-2168.

75. Fajans, S.S., Floyd, J.C., Knopf, R.F., and Conn, F.W. 1967. Effect of amino acids and proteins on insulin secretion in man. Recent Prog. Horm. Res. 23:617-662.

76. Gloyn, A.L., et al. 2003. Insights into the biochemi$\mathrm{cal}$ and genetic basis of glucokinase activation from naturally occurring hypoglycemia mutations. Diabetes. 52:2433-2440.

77. Miki, T., Iwanaga, T., Nagashima, K., Ihara, Y., and Seino, S. 2001. Roles of ATP-sensitive $\mathrm{K}^{+}$channels in cell survival and differentiation in the endocrine pancreas. Diabetes. 50(Suppl. 1):S48-S51.

78. Shield, J.P.H. 1996. Neonatal diabetes. In Childhood diabetes. Volume 4. J.H. Shield and J.D. Baum, editors. Baillière Tindall. London, United Kingdom. 681-740.

79. Gloyn, A.L., et al. 2002. Complete glucokinase deficiency is not a common cause of permanent neonatal diabetes [letter]. Diabetologia. 45:290.

80. Njølstad, P.R., et al. 2001. Neonatal diabetes mellitus due to complete glucokinase deficiency. N. Engl. J. Med. 344:1588-1592.

81. Temple, I.K., et al. 1995. An imprinted gene(s) for diabetes? Nat. Genet. 9:110-112.

82. Zung, A., Glaser, B., Nimri, R., and Zadik, Z. 2004. Glibenclamide treatment in permanent neonatal diabetes mellitus due to an activating mutation in Kir6.2. J. Clin. Endocrinol. Metab. 89:5504-5507.

83. Proks, P., et al. 2004. Molecular basis of Kir6.2 mutations associated with neonatal diabetes or neonatal diabetes plus neurological features. Proc. Natl. Acad. Sci. U. S. A. 101:17539-17544.

84. Peter Proks, P., et al. 2005. A gating mutation at the internal mouth of the Kir6.2 pore is associated with DEND syndrome. EMBO Rep. 6:470-475.

85. Nahi-Buisson, N., et al. 2004. Early epileptic encephalopathy and neonatal diabetes, associated with mutation in ATP-sensitive potassium channel, Kir6.2. Am. J. Hum. Genet. 75(Suppl. 1):323.

86. Yorifuji, T., et al. 2005. The C42R mutation in the Kir6.2 (KCNJ11) gene as a cause of transient neonatal diabetes, childhood diabetes, or later-onset, apparently type 2 diabetes mellitus. J. Clin. Endocrinol. Metab. doi:10.1210/jc.2005-0096.

87. Nichols, C.G., and Lederer, W.J. 1990. The regulation of ATP-sensitive $\mathrm{K}^{+}$channel activity in intact and permeabilized rat ventricular myocytes. J. Physiol. 423:91-110.

88. Watts, A.E., Hicks, G.A., and Henderson, G. 1995. Putative pre- and postsynaptic ATP-sensitive potassium channels in the rat substantia nigra in vitro. J. Neurosci. 15:3065-3074.

89. Deist, M., Repp, H., and Dreyer, F. 1992. Sulfonylurea-sensitive $\mathrm{K}^{+}$channels and their probable role for the membrane potential of mouse motor nerve endings. Pflugers Arch. 421:292-294.

90. Koster, J.C., et al. 2001. Tolerance for ATP-insensitive $\mathrm{K}_{(\mathrm{ATP})}$ channels in transgenic mice. Circ. Res. 89:1022-1029.

91. John, S.A., Weiss, J.N., Xie, L.H., and Ribalet, B. 2003. Molecular mechanism for ATP-dependent closure of the K+ channel Kir6.2. J. Physiol. 552:23-34.

92. Trapp, S., Proks, P., Tucker, S.J., and Ashcroft, F.M. 1998. Molecular analysis of $K_{\mathrm{ATP}}$ channel gating and implications for channel inhibition by ATP. J. Gen. Physiol. 112:333-349.

93. Markworth, E., Schwanstecher, C., and Schwanstecher, M. 2000. ATP4- mediates closure of pancreatic beta-cell ATP-sensitive potassium channels by interaction with 1 of 4 identical sites. Diabetes. 49:1413-1418. 
94. Fajans, S.S., Bell, G.I., and Polonsky, K.S. 2001. Molecular mechanisms and clinical pathophysiology of maturity-onset diabetes of the young. $N$. Engl. J. Med. 345:971-980.

95. Dukes, I.D., et al. 1998. Defective pancreatic ( $\beta$-cell glycolytic signaling in hepatocyte nuclear factor1 $\alpha$-deficient mice. J. Biol. Chem. 273:24457-24464.

96. van den Ouweland, J.M., et al. 1992. Mutation in mitochondrial tRNA(Leu)(UUR) gene in a large pedigree with maternally transmitted type II diabetes mellitus and deafness. Nat. Genet. 1:368-371.

97. van den Ouweland, J.M., Maechler, P., Wollheim, C.B., Attardi, G., and Maassen J.A. 1999. Functional and morphological abnormalities of mitochondria harbouring the tRNA(Leu)(UUR) mutation in mitochondrial DNA derived from patients with maternally inherited diabetes and deafness (MIDD) and progressive kidney disease. Diabetologia. 42:485-492.

98. Hani, E.H., et al. 1998. Missense mutations in the pancreatic islet beta cell inwardly rectifying $\mathrm{K}^{+}$ channel gene (Kir6.2/BIR): a meta-analysis suggests a role in the polygenic basis of type II diabetes mellitus in Caucasians. Diabetologia. 41:1511-1515.

99. Gloyn, A.L., et al. 2003. Large-scale association studies of variants in genes encoding the pancreatic $\beta$-cell $\mathrm{K}_{\mathrm{ATP}}$ channel subunits Kir6.2 (KCNJ11) and SUR1 (ABCC8) confirm that the KCNJ11 E23K variant is associated with type 2 diabetes. Diabetes. 52:568-572.

100.Barroso, I., et al. 2003. Candidate gene association study in type 2 diabetes indicates a role for genes involved in $\beta$-cell function as well as insulin action. PLoS Biol. 1:41-55.

101.Schwanstecher, C., Meyer, U., and Schwanstecher, M. 2003. K(IR) 6.2 polymorphism predisposes to type 2 diabetes by inducing overactivity of pancreatic $\beta$-cell ATP-sensitive $\mathrm{K}^{+}$channels. Diabetes.
51:875-879.

102.Schwanstecher, C., Neugebauer, B., Schulz, M., and Schwanstecher, M. 2002. The common single nucleotide polymorphism E23K in K(IR)6.2 sensitizes pancreatic $\beta$-cell ATP-sensitive potassium channels toward activation through nucleoside diphosphates. Diabetes. 51(Suppl. 3):S363-S367.

103.Reidel, M.J., Boora, P., Steckley, D., de Vries, G., and Light, P.E. 2003. Kir6.2 polymorphisms sensitize beta-cell ATP-sensitive potassium channels to activation by acyl CoAs: a possible cellular mechanism for increased susceptibility to type 2 diabetes? Diabetes. 52:2630-2635.

104.Nielsen, E.M., et al. 2003. The E23K variant of Kir6.2 associates with impaired post-OGTT serum insulin response and increased risk of type 2 diabetes. Diabetes. 52:573-577.

105.Florez, J.C., et al. 2004. Haplotype structure and genotype-phenotype correlations of the sulfonylurea receptor and the islet ATP-sensitive potassium channel gene region. Diabetes. 53:1360-1368.

106. Tschritter, O., et al. 2002. The prevalent Glu23Lys polymorphism in the potassium inward rectifier 6.2 (KIR6.2) gene is associated with impaired glucagon suppression in response to hyperglycemia. Diabetes. 51:2854-2860.

107. Triggs-Raine, B.L., et al. 2002. HNF-1 $\alpha$ G319S, a transactivation-deficient mutant, is associated with altered dynamics of diabetes onset in an Oji-Cree community. Proc. Natl. Acad. Sci. U. S. A. 99:4614-4619.

108.Stone, L.M., Kahn, S.E., Fujimoto, W.Y., Deeb, S.S., and Porte, D., Jr. 1996. A variation at position -30 of the $\beta$-cell glucokinase gene promoter is associated with reduced $\beta$-cell function in middle-aged Japanese-American men. Diabetes. 45:422-428.

109. Weedon, M.N., et al. 2004. Common variants of the hepatocyte nuclear factor-4alpha P2 promoter are associated with type 2 diabetes in the U.K. population. Diabetes. 53:3002-3006.

110.Sesti, G., et al. 2003. A common polymorphism in the promoter of UCP2 contributes to the variation in insulin secretion in glucose-tolerant subjects. Diabetes. 52:1280-1283.

111.Poulton, J., et al. 2002. Type 2 diabetes is associated with a common mitochondrial variant: evidence from a population-based case-control study. Hum. Mol. Genet. 11:1581-1583.

112.Maechler, P., and Wollheim, C.B. 2001. Mitochondrial function in normal and diabetic $\beta$-cells. Nature. 414:807-812.

113.Petersen, K.F., et al. 2003. Mitochondrial dysfunction in the elderly: possible role in insulin resistance. Science. 300:1140-1142.

114.Michikawa, Y., Mazzucchelli, F., Bresolin, N., Scarlato, G., and Attardi, G. 1999. Aging-dependent large accumulation of point mutations in the human mtDNA control region for replication. Science. 286:774-779.

115.Campbell, J.D., Proks, P., Lippiat, J.D., Sansom, M.S.P., and Ashcroft, F.M. 2004. Identification of a functionally important negatively charged residue within the second catalytic site of the SUR1 nucleotide binding domains. Diabetes. 53(Suppl. 3): S123-S127.

116.Antcliff, J., Haider, S., Proks, P., Sansom, M., and Ashcroft, F.M. 2005. Functional analysis of a structural model of the ATP-binding site of the $\mathrm{K}_{\mathrm{ATP}}$ channel Kir6.2 subunit. EMBO J. 24:229-239.

117. Reimann, F., et al. 2003. Characterisation of new $\mathrm{K}_{\mathrm{ATP}}$-channel mutations associated with congenital hyperinsulinism in the Finnish population. Diabetologia. 46:241-249.

118. Huopio, H., et al. 2002. Acute insulin response tests for the differential diagnosis of congenital hyperinsulinism. J. Clin. Endocrinol. Metab. 87:4502-4507. 